\title{
Lipodystrophies in Children
}

\author{
Francesca Mainieri Francesco Chiarelli \\ Department of Paediatrics, University of Chieti, Chieti, Italy
}

\section{Keywords}

Lipodystrophy · Adipose tissue - Insulin resistance · Metabolic syndrome

\begin{abstract}
Background: Lipodystrophy includes a wide group of diseases characterized by reduction, absence, or altered distribution of adipose tissue. Lipodystrophies are classified into generalized or partial, according to the fat distribution, and congenital or acquired, considering the etiology. Summary: Impaired glucose and lipid metabolism are typically present, thus severe insulin resistance, diabetes mellitus, dyslipidemia, and hepatic steatosis are frequent complications. Because of the rarity and the diversification of lipodystrophies, diagnosis might be challenging, typically for partial forms that cannot be easily recognized, leading to progression of the several metabolic abnormalities associated. First management of lipodystrophy is diet and lifestyle changes, followed by the treatment of metabolic complications. Replacement therapy with metreleptin, currently available in the USA and Europe, has shown improvement of metabolic profile in a great number of patients with lipodystrophy. Key Messages: The purpose of this review was to describe the phenotypic characteristics of all the known lipodystrophic types and to present specific steps for obtaining an early diagnosis and assessing the best treatment of lipodystrophy.
\end{abstract}

(c) 2022 S. Karger AG, Basel (c) 2022 S. Karger AG, Basel

www.karger.com/hrp

\section{Introduction}

Lipodystrophies are a heterogenous group of infrequent conditions characterized by the constant feature of a lack or dysfunction of white adipose tissue associated or not to perturbation in its mass or distribution. Considering the etymology, lipodystrophy derives from Latin; in particular, lipo means "fat" and dystrophy stands for "degenerative condition." Thus, lipodystrophy represents an impaired lipid metabolism [1]. They can be genetic or acquired syndromes, according to their origin. According to the distribution, lipodystrophies are classified as generalized, partial, or localized in small areas [2].

A large number of cases are related to metabolic conditions, such as insulin resistance, nonalcoholic fatty liver disease, dyslipidemia, predisposition to atherosclerosis and cardiovascular diseases, polycystic ovarian syndrome, acanthosis nigricans, and their sequelae, as it results in an increased risk of obesity [3]. Thus, both lipodystrophic and obese patients, who have opposite body weight characteristics, may present the same metabolic complications. Most patients with lipodystrophy are lean or nonobese. The greater the fat loss, the more frequent the metabolic complications [4]. Furthermore, recent evidence highlights the presence of similar mechanisms leading to insulin resistance in lipodystrophies and obesity, suggesting a similarity in the treatment for these two conditions as well, such as bariatric surgery [5-7]. Even though lipo-

\footnotetext{
Karger'"
}

Correspondence to:

Francesca Mainieri, francesca.mainieri@outlook.it 
dystrophies are very rare, they are useful for a more complete understanding of adipose tissue metabolism and of the pathophysiology of metabolic syndrome [8].

Lipodystrophy syndromes are due to different molecular causes, which reflect both clinical heterogeneity and similar pathophysiological relationships of these diseases. Besides the diversity of clinical forms, all these syndromes share adipose tissue dysfunction as the common pathophysiological feature, with gene pathogenic variants principally affecting adipocyte development, differentiation, and/or functions [9].

The prevalence of lipodystrophies, according to current data [10], corresponds to 1.3-4.7 cases per million in the general population, excluding HIV-infected patients with highly active antiretroviral therapy-induced lipodystrophy, even fewer for genetic lipodystrophies [11]. The most prevalent types of inherited lipodystrophies are

Table 1. Clinical manifestations arising the suspicion of lipodystrophy

Patients with regional or generalized lack of adipose tissue outside of the normal range

- Familial and clinical history of lipodystrophy

- Failure to thrive

- Cushingoid/acromegaloid/progeroid appearance

- Prominent muscle and veins (phlebomegaly)

- Eruptive xanthomata

- Metabolic complications (diabetes mellitus with high insulin requirements, severe hypertriglyceridemia and consequent acute pancreatitis, nonalcoholic steatohepatitis in lean patients, early-onset cardiomyopathy, polycystic ovary syndrome)

- Hyperphagia congenital generalized lipodystrophy (CGL) and familial partial lipodystrophy (FPLD), numbers being about 300500 patients each. Among the acquired syndromes, the most prevalent are acquired generalized lipodystrophy (AGL) and acquired partial lipodystrophy (APL) [10]. In contrast with these data, other subtypes of lipodystrophies are very rare as are present in just 30 patients at the most: mandibuloacral dysplasia (MAD), progeroid syndromes associated lipodystrophy, autoinflammatory lipodystrophy, SHORT syndrome associated lipodystrophy, and Keppen-Lubinsky syndrome associated lipodystrophy belong to this group [12].

This review aims to raise awareness and broaden knowledge of lipodystrophies and especially clinical manifestations which should raise suspicion of lipodystrophy syndromes and would lead subsequently to further testing (Table 1). Although these conditions are uncommon, it is important to fully define their suggestive clinical and laboratorial findings in order to help pediatricians to make a correct diagnosis.

\section{Genetic Lipodystrophies}

Genetic lipodystrophies can be divided into generalized or partial (Tables 2-4). This panel of syndromes is commonly linked to severe insulin resistance. There are four CGL syndromes identified so far, all with an autosomal recessive pattern of transmission. By contrast, six FPL forms are described, each with a precise inheritance pattern [13]. The typical distribution of adipose tissue loss in the main lipodystrophy syndromes is shown in Figure 1.

Table 2. CGLs

\begin{tabular}{llll}
\hline $\begin{array}{l}\text { Syndrome and } \\
\text { gene involved }\end{array}$ & Inheritance & Mechanism classification & Clinical features \\
\hline CGL1 (AGPAT2) & $\begin{array}{l}\text { Autosomal } \\
\text { recessive }\end{array}$ & Malfunction of triglyceride synthesis & $\begin{array}{l}\text { Nearly total lack of adipose tissue from birth, severe IR, } \\
\text { hypertriglyceridemia, NAFLD }\end{array}$ \\
\hline CGL2 (BSCL2) & $\begin{array}{l}\text { Autosomal } \\
\text { recessive }\end{array}$ & $\begin{array}{l}\text { Lipid droplet dysfunction and/or } \\
\text { compromised adipogenesis }\end{array}$ & $\begin{array}{l}\text { Phenotype as CGL1, plus cardiomyopathy and intellectual } \\
\text { disability }\end{array}$ \\
\hline CGL3 (CAV1) & $\begin{array}{l}\text { Autosomal } \\
\text { recessive }\end{array}$ & Disturbed caveolar function & $\begin{array}{l}\text { Neonatal absence of adipose tissue, severe IR, dyslipidemia, } \\
\text { pulmonary hypertension, short stature }\end{array}$ \\
\hline CGL4 (PTRF) & $\begin{array}{l}\text { Autosomal } \\
\text { recessive }\end{array}$ & Disturbed caveolar function & $\begin{array}{l}\text { Loss of adipose tissue, hypertrophic cardiomyopathy, skeletal } \\
\text { myopathy, less severe IR }\end{array}$ \\
\hline
\end{tabular}

NAFLD, nonalcoholic fatty liver disease. 


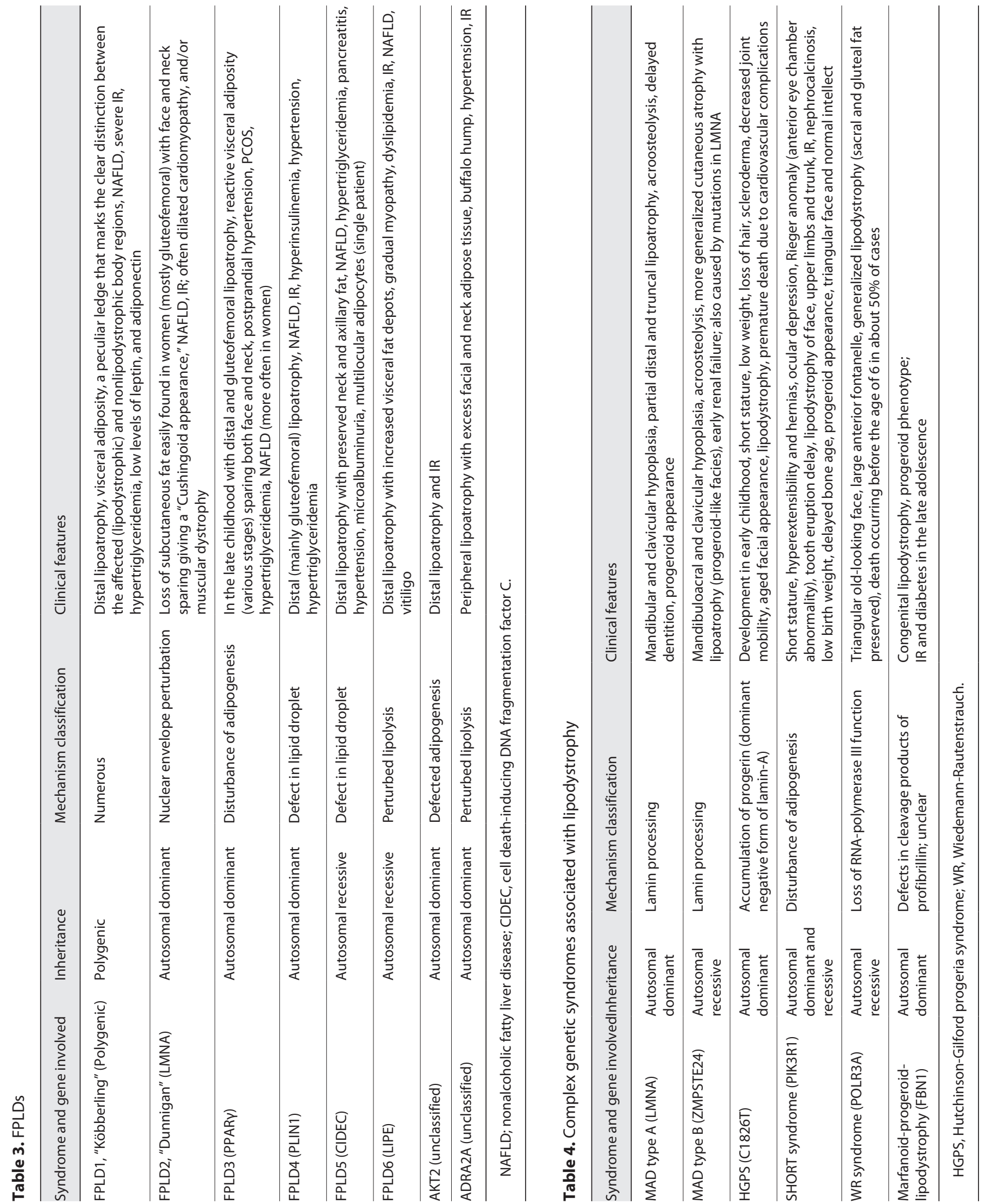




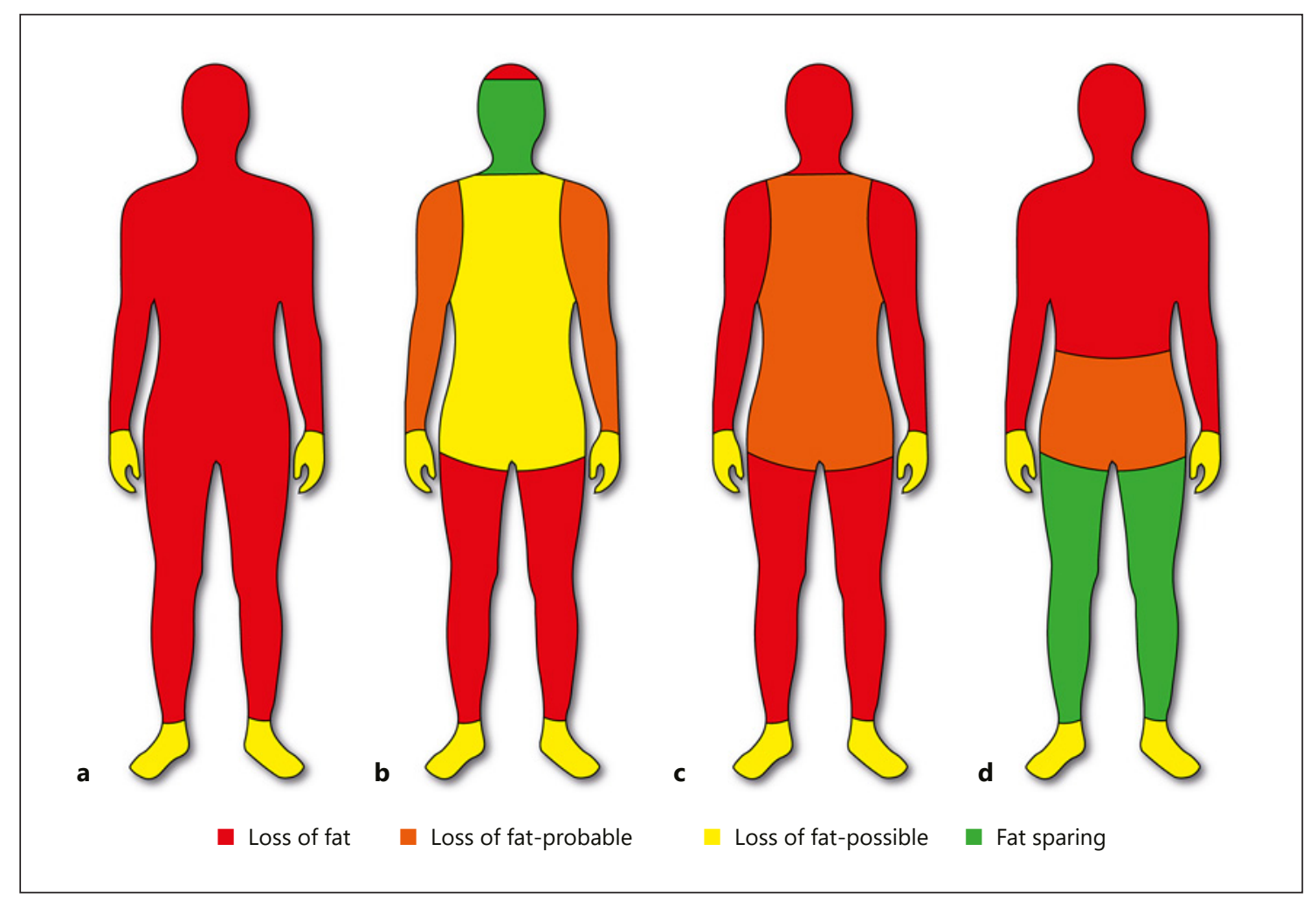

Fig. 1. Distribution of adipose tissue loss in lipodystrophy syndromes. a CGL. b FPL. c AGL. d APL.

\section{Congenital Generalized Lipodystrophy}

CGL is a disorder that presents early, at birth, or just after, characterized by a near-complete lack of adipose tissue and a paradoxical muscularity. The prevalence in the general population is about 1 in 10 million [14]. There are several cases reported in consanguineous people, in particular in families from Brazil, Lebanon, Scandinavia, and African ancestry, probably because of the high rate of founder mutations and endogamy in these ethnic groups [15].

CGL diagnostic criteria were proposed a couple of decades ago, on the basis of the scientific literature, suggesting conventional anthropometry, including measurements of skinfold thickness by calipers and a whole-body magnetic resonance imaging to confirm the characteristic adipose tissue distribution [16]. Since then, with improved knowledge and updates, a molecular diagnosis based on genotyping has been added as a confirmatory step [17]. CGL patients have peculiar clinical features (Table 5) [18-20].

Insulin resistance is one of the major findings of lipodystrophies, together with associated metabolic condi- tions. Hyperinsulinemia is nearly always present and $45 \%$ of these patients develop diabetes mellitus during puberty. Diabetes mellitus is ketosis resistant, probably due to the endogenous hyperinsulinemia, and needs high insulin doses to reach a good glycemic control (up to 3,000 units a day) [21]. In those subjects with impaired diabetic control, hypertriglyceridemia develops in more than $70 \%$ of CGL patients and might lead to eruptive xanthomas and pancreatitis. Lipidic profile is also affected, showing low levels of HDL cholesterol and mild to severe hypertriglyceridemia, a typical condition of late childhood [22]. Some patients may have focal segmental glomerulosclerosis, mental retardation, and/or cardiovascular diseases, in particular cardiomyopathy [23].

An increased risk of pathological fractures is usually present after puberty in the long bones, such as humerus, femur, radius, ulna, carpal, tarsal, or phalangeal bones, with lytic lesions. Focal lytic bone lesions may be explained since there are problems in making normal bone marrow fat to replace hematopoietic marrow in children and can be confused with polyostotic fibrous dysplasia [24]. Advanced bone age might be associated with these clinical conditions [25]. 
Table 5. Clinical features of CGL

\begin{tabular}{ll}
\hline $\begin{array}{l}\text { Lipodystrophy } \\
\text { syndrome }\end{array}$ & Clinical features \\
\hline $\mathrm{CGL}$ & - Acromegaloid features (enlarged mandibles) \\
- & Muscular appearance in both hands and feet \\
- & Accelerated growth \\
- & A voracious appetite, usually caused by severe hypoleptinemia \\
- & Hepatomegaly and/or splenomegaly, probably inducing the prominence of umbilicus or \\
& umbilical hernia \\
- & Liver enlargement due to the hepatic steatosis, progressing to the worse state of \\
& steatohepatitis, then fibrosis and cirrhosis and finally end-stage liver disease and \\
transplantation & Acanthosis nigricans mostly affecting the neck, axillae, and groin regions, with onset \\
during early childhood or after puberty & Women with CGL may develop hirsutism, clitoromegaly, amenorrhea (primary or \\
& secondary)
\end{tabular}

\section{CGL Subtypes}

There are four specific genes reported to be part of CGL (Table 2). Berardinelli-Seip syndrome takes its name from the authors who first discovered it, respectively Berardinelli [26] in Brazil in 1954 and then Seip [27] in Scandinavia in 1959. It is a very rare autosomal recessive disorder, often affecting subjects belonging to consanguineous families. Two forms of the syndrome have been described (CGL1 and CGL2), each involving different genetic patterns.

\section{Type 1 CGL}

The type 1 CGL (CGL1) syndrome is caused by a biallelic disease-causing mutations in AGPAT2, a gene located on chromosome 9q34 which encodes for 1-acylglycerol-3-phosphate acyltransferase 2. This enzyme is a key component of the phospholipids and triglycerides synthesis [28]. Together with the CGL2, it is the most common subtype, reported in about 200-250 patients. Among the several isoforms, AGPAT2 is most expressed in adipose tissue; hence, a deficiency can cause lipodystrophy [29].

Different types of AGPAT2 mutations have been registered; however, no correlation between genotype and both severity of fat loss and the phenotype has been documented. Affected patients with CGL1 present mechanical adipose tissue in the palms of the hands and soles of the feet, orbit, under the scalp, vulva, perineum, periarticular, and pericalyceal regions of the kidneys. In contrast, the lack of metabolically active adipose tissue has been documented in most subcutaneous areas, such as intra-abdominal and intrathoracic regions and bone marrow [30]. Available data have shown a compensatory increased expression of the other AGPAT isoforms which explain the remaining of the small part of fat documented. These patients present acromegaloid features involving mandibles, hands, and feet. AGPAT2 metabolic pathway seems to have a role in adipocytes differentiation [31]. A more recent study has shown that AGPAT2 is involved in the regulation of the early steps of adipogenesis, due to the modulation of lipoma [32]. Furthermore, a decrease in phosphatidylinositol synthesis has been documented, thus affecting the metabolic actions of insulin, such as glucose transport, in the liver, skeletal muscle, but especially in the adipose tissue [33].

\section{Type 2 CGL}

The second form is type 2 CGL which is related to mutations in BSCL2 gene on chromosome 11q13, which encodes seipin, a 398 amino acid transmembrane protein. Seipin has a key role in the lipid droplets assembly and adipocytes differentiation [34]. Specifically, seipin is an oligomeric integral membrane protein, within the endoplasmic reticulum, that concentrates at junctions with cytoplasmic lipid droplets [35]. Lipid homeostasis is guaranteed thanks to seipin by reducing lipogenesis and lipid droplet accumulation in nonadipocytes, whereas promoting adipogenesis in periods of excess energy storage. Thus, adipocyte maturation is rigorously blocked in case of seipin dysfunction [36]. Seipin can interact with AGPAT2 through the binding of phosphatidic acid phosphatase LPIN1 (also known as lipin1) and this could explain the involvement of seipin in the synthesis of phospholip- 
ids and triglyceride as well [37]. Null and missense mutations are reported, but there are no apparent phenotypic differences between these two genetic alterations.

Patients with CGL2 have a deficiency of not only metabolically relevant adipose tissue, similarly to CGL1, but also mechanically important adipose tissue (for instance, on the palms and soles). Therefore, CGL2 is the most severe form of CGL [38]. Cardiomyopathy, mild mental retardation, lower median serum levels of leptin and adiponectin than general populations are reported as possible findings in CGL2 [39]. Teratozoospermia has been identified in a single patient with CGL2. Neurological impairment can be manifested by spastic gait related to upper motor lesion reported in 3 patients of a Pakistani family, fatal neurodegenerative syndrome, or distal hereditary motor neuropathy [40].

\section{Type 3 CGL}

Type 3 CGL is linked to mutations in CAV1, which is located on chromosome $7 \mathrm{q} 31$ and encodes caveolin 1 [41]. Caveolin 1 is a key essential component for the function of the caveolae and is a particular microdomain of the lipid rafts of the plasma membrane. Caveolae are invaginations of the plasma membrane involved in endocytosis, signal transmission, formation of fat droplets, binding, transport, and/or storage of fatty acids and cholesterol, increase insulin signaling [42]. CAV1 is mostly expressed in adipocytes, fibroblast, and endothelial cells, even if is ubiquitously found [43]. The function of CAV1 is central to obtain a high number of caveolae, to let a great amount of large lipid droplets to be contained in adipocytes, and to regulate intracellular cholesterol fluxes between cellular compartments [44]. This kind of generalized lipodystrophy has been reported in a homozygous nonsense mutation in a young woman from Brazil. The phenotype was characterized by short stature, functional megaesophagus, and hypocalcemia (probably secondary to vitamin $\mathrm{D}$ resistance). In addition, acanthosis nigricans, hypertriglyceridemia, primary amenorrhea, chronic diarrhea, hepatic steatosis, and splenomegaly, diabetes mellitus were also reported. Metabolic adipose tissue was absent, but mechanical adipose tissue, as well as the fat present in the bone marrow, were normal [42].

\section{Type 4 CGL}

Mutations in polymerase I and transcript release factor (PTRF), which is located in chromosome 17q21.2, are responsible for type 4 CGL. PTRF encodes PTRF or also called cavin-1. Cavin-1 is a necessary factor in the biogenesis of caveolae and co-localizes with caveolin 1 in the adipocytes [45]. Caveolae are stabilized in their own structures due to the interaction between cavin-1 and the cell's cytoskeleton. Cavin-1 provides for the differentiation of adipocytes and adipose tissue expandability [46]. About 30 patients with this CGL subtype have been reported. Clinical features are osteopenia and distal metaphyseal deformation with joint stiffness, pyloric stenosis, atlantoaxial instability, percussion induced. The skeletal, and cardiac muscles are also affected, therefore, patients might have congenital myopathy with high creatine kinase serum levels, local protracted muscle contractions (also known as "mounding"), and severe arrhythmias (such as long QT syndrome, catecholaminergic polymorphic ventricular tachycardia) with sudden cardiac death [47]. The progression of adipose tissue loss during infancy is also typical. In a lower number of cases, nephrosis, transient immunoglobulin A deficiency, and presence of mechanical and bone marrow fat have been reported [48]. Patients have hepatomegaly and metabolic abnormalities such as hypertriglyceridemia, hepatic steatosis, hyperinsulinemia, and insulin resistance, although clear evidence of diabetes has not been described [49].

\section{Familial Partial Lipodystrophy}

FPLD was first described in the 1970s, although its comprehension has only been improved recently, due to new knowledge on genetic and biology of adipose tissue and the discovery of the leptin gene [50]. Up to this point, six subtypes of FPLD have been identified, but there are other unclassified forms of partial lipodystrophy linked to rare genetic syndromes, each with a different phenotype [51]. FPLD is typically autosomal dominant disorders characterized by a late development of lack of adipose tissue (late childhood or puberty) in the extremities, upper and lower, and the trunk. The partial loss of adipose tissue is typically more pronounced over time. As a matter of fact, FPLD might be underestimated in childhood since most patients start to lose adipose tissue after puberty [52].

Findings of fat tissue in several ectopic regions of the body, such as liver, muscle, pancreas, blood vessels, and a distorted secretion of adipokine lead to the onset of insulin resistance and abnormalities in both lipid and glucose metabolism [53]. The explanation is that in lipodystrophy the adipocytes can host the development of oxidative stress, macrophage infiltration, lipotoxicity, and mitochondrial dysfunction since they are malfunctioning and adipose tissue lacks its congenital capacity to expand [54]. 
The levels of leptin and adiponectin, which are typically low in lipodystrophy, are in part related to the metabolic and reproductive changes, particularly in those patients with nearly absent adipose tissue. New evidence suggests that leptin has a primary central action on human reproductive function, but an indirect health effect on genital tissues, such as ovaries and prostate glands, even though some leptin receptors are reported at this level [55] In general, the more extended the lipoatrophy, the more relevant the metabolic imbalance. Diabetes and cardiovascular disease are more closely connected to insulin resistance due to low levels of adiponectin, while hyperphagia is a consequence of low leptin levels [56]. A tissue-specific effect in the insulin action has been recently reported, due to promoter effect in the increased gluconeogenesis and lipogenesis and to a reduction of peripheral glucose uptake. These effects result in the inhibition of insulin signaling in liver and muscle and are the cause of the development of the representative metabolic complications found in lipodystrophy [57]. However, insulin continues to induce hyperandrogenemia and acromegaloid features thanks to its still present mitogenic effect on ovarian theca cells and its anabolic action, respectively [58]. In view of these novel findings, the genetically determined alteration of these pathophysiological mechanisms is similar in metabolic syndrome and lipodystrophy syndrome [51].

\section{FPLD Subtypes}

Scientific research on genetic patterns of FPLD has been intensified recently (Table 3 ). However, there are still subjects with a clear phenotype of lipodystrophy who do not express the known mutations. This suggests that new genes have yet to be identified [59]. The inheritance is typically autosomal dominant, but there are very rare patients who present autosomal recessive inheritance.

\section{FPLD type 2}

Dunnigan syndrome is the most common type of FPLD and the genetic basis is related to chromosome 1q21-22 [60]. It is due to molecular changes in the lamin A/C (LMNA) gene. Lamins A and C are intermediate filament proteins that form hetero- and homodimeric structures of the nuclear lamina and polymeric structures between chromatin and the nuclear envelope. These structures represent an important step in the maintenance of nuclear function and stability. The resulting altered interaction of lamina and chromatin can explain the reduced number of fat cells and can also provoke an in- creased premature apoptosis [61]. About $75 \%$ of patients have the "typical" Dunnigan syndrome with a missense mutation affecting the arginine residue at 482 positions, characterized by a severe phenotype, instead patients with milder features belong to the "atypical" form with mutations in other positions [62]. The onset is gradual, so the main characteristics are documented only during puberty, when high rates of hormones tend to expand the fat depots [2]. Furthermore, women are more frequently hit by severe insulin resistance compared to men, leading to hepatic steatosis, hypertriglyceridemia, and acanthosis nigricans [63]. The signaling pathways affected by FPLD2associated LMNA mutations contribute to the onset of metabolic dysfunction and cardiovascular disease [64]. In particular, LMNA gene mutations may be linked to other diseases, such as dilated cardiomyopathy, different forms of muscular dystrophy, and proteinuric nephropathy [65-67].

\section{FPLD type 3}

Variants of type FPLD3 are associated with heterozygous mutations in the peroxisome proliferator-activated receptor $\gamma(\operatorname{PPAR} \gamma)$ gene, an important transcription factor in adipocyte differentiation. This gene is a major regulator of adipogenesis, by creating more and smaller adipocytes, and adipose tissue maintenance [68]. Agarwal and Garg [69] were the first to report the association between peroxisome PPAR $\gamma$ mutation and FPLD phenotype. Comparing to FPLD2, these patients have a lower rate of lipodystrophy, therefore have milder metabolic complications and paucity of cardiovascular disease as well [70]. On the other hand, there is no statistically significant difference in the prevalence of hypertension and diabetes mellitus in males and females with FPLD3 [71].

\section{FPLD type 1}

FPLD type 1, also known as Köbberling-Type lipodystrophy, is characterized by lipodystrophy along the extremities and increased amount of facial, neck, and visceral fat tissue [72]. The genetic origin of this syndrome has not completely been identified, thus a polygenic pathway has been suggested [73]. According to the clinical features, it seems quite similar to Dunnigan syndrome (FPLD2) and/or FPLD3, so diagnosis is based on clinical signs and exclusion of the other lipodystrophic types [74].

\section{FPLD types 4, 5, 6, 7}

All these types of FPLD have in common the involvement of genes that play a role in droplet formation and lipolysis. FPLD4 represents variants caused by the perili- 
pin 1 (PLIN1), a structural protein of adipocyte that coats lipid droplets and regulates lipolysis by monitoring intracellular lipases [75]. Therefore, PLIN1 is involved in the stabilization of lipids in a chemically inert form for the cell [76]. Autosomal dominant frameshift mutations causing the loss of function of PLIN1 have been connected to FPLD4. These variants are characterized by lipoatrophy especially of gluteofemoral and subcutaneous fat of the lower limbs, facial acromegaloid features, and muscular hypertrophy [77]. Insulin resistance, hyperinsulinemia, nonalcoholic fatty liver disease, hypertriglyceridemia, and hypertension can be found in these patients. The predisposition to developing metabolic syndrome seems linked to the rising lipotoxicity due to increased unregulated release of lipid into the cell [78]. Null variants of PLIN1 have been found in diabetic/hyperinsulinemic patients with no presentation of lipodystrophy, suggesting the lack of a real pathogenetic role [79].

FPLD5 is due to mutations of the protein cell deathinducing DNA fragmentation factor $\mathrm{C}$ which induces the formation of unilocular fat droplets by transferring lipids from the smaller to the larger droplets [80]. Up to now, one single patient with partial lipodystrophy secondary to nonsense cell death-inducing DNA fragmentation factor $\mathrm{C}$ mutations has been identified and presented lack of subcutaneous fat from the extremities and femoro-gluteal region. In contrast, fat is present in visceral and neck areas [57]. Similarities between FPLD5 and FPLD4 have been established relatively to phenotypic manifestations [81].

LIPE is the gene that encodes hormone-sensitive lipase, the enzyme responsible for hydrolyzing esters to free fatty acids. This enzyme is extremely expressed in adipose tissue and its mutations are the cause of FPLD6 [82]. In addition to metabolic manifestations, vitiligo has been reported [83]. FPLD7 is related to mutations in the caveolin gene (CAV1). Akt2-coupled lipodystrophy, very rare, is linked to an autosomal dominant mutation in AKT2, a protein intermediate in insulin signaling [84].

\section{FPLD in Rare Diseases (Table 4)}

MAD is a rare systemic disorder. Growth retardation, skeletal abnormality with progressive osteolysis of the distal phalanges and collarbones, craniofacial anomalies with mandibular hypoplasia, a "bird's face" with protruding eyes, and a curved nose, lipodystrophy, and mottled skin are described [85]. Some of these patients might present progeroid characteristics. Two types have been described: MAD type $\mathrm{A}$, in which patients have partial loss of subcutaneous fat from the extremities, and MAD type $\mathrm{B}$, in which the loss is more generalized, involving face, trunk, and extremities too [86]. A homozygous missense mutation in the C-terminal domain of lamins A/C is the most common defect found in MAD type A. In contrast, heterozygous compounds mutations in the zinc metalloproteinase (ZMPSTE24) gene cause MAD type B. This protease processes lamin A from pre-lamin A, so if it is malfunctioning, pre-lamin A tends to accumulate, leading to toxicity and cellular senescence. There are MAD patients who do not present the mutations described, thus postulating the contribution of new genes [87].

Hutchinson-Gilford progeria syndrome is probably the best known progeroid syndrome, caused by a single nucleotide polymorphism (C1826T) in the lamin A/C gene. The mutation determines the accumulation of progerin, which is the mutated pre-lamin A. The syndrome is characterized by short stature, low weight, loss of hair, scleroderma, decreased joint mobility, aged facial appearance, and lipodystrophy [88]. It develops in early childhood and is associated with premature death due to cardiovascular complications. As reported, MAD type A and Hutchinson-Gilford progeria syndrome share mutations in the same gene; therefore, they are usually considered two sides of the same syndrome, differentiating by the severity of the manifestations [89].

SHORT is a rare syndrome, whose name is the acronym of the characteristics present in this disease, namely short stature, hyperextensibility of joints and/or inguinal hernia, ocular depression, Rieger anomaly (iris and tooth abnormalities), and teething delay [90]. The mutation is in the subunit of p85 phosphatidylinositol 3-kinase (PI$\mathrm{K} 3 \mathrm{R} 1$ ), an enzyme that provides cellular signaling of insulin [91]. Some patients can present insulin resistance and diabetes [92].

Progeroid appearance is the typical characteristic in Wiedemann-Rautenstrauch syndrome and MarfanoidProgeroid-Lipodystrophy syndrome. WiedemannRautenstrauch is a neonatal progeria syndrome, caused by mutation on POLR3A gene. Patients present a triangular and old-looking face, large anterior fontanelle, and generalized lipodystrophy, with specific preservation of fat in the sacral and gluteal areas [93]. MarfanoidProgeroid-Lipodystrophy is a novel marfanoid entity involving congenital lipodystrophy, a neonatal progeroid appearance, a particular growth pattern, due to mutations in the penultimate exon of FBN1 [94]. 
Fig. 2. AGL: progression of fat loss over time at the age of 4.5 months (a), 6 months (b), 8 months (c), and 10 months (d). Image reprinted from reference [95] (Misra A, Garg A. Clinical features and metabolic derangements in acquired generalized lipodystrophy case reports and review of the literature. Medicine. 2003). Copyright 2003, with permission from Lippincott Williams and Wilkins.
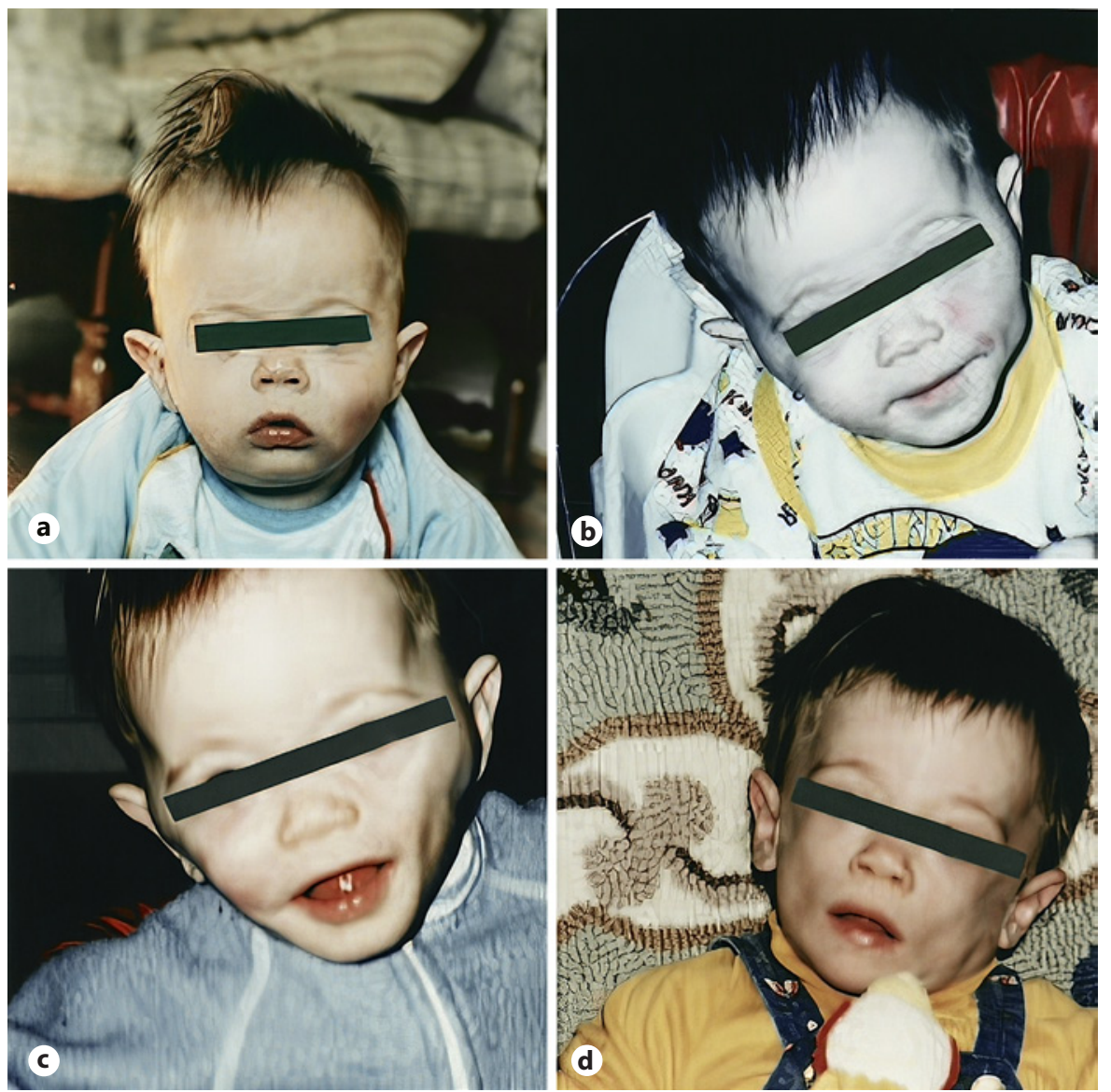

Table 6. AGL (Lawrence syndrome) and APLs

\begin{tabular}{llll}
\hline Syndrome & Inheritance & Mechanism classification & Clinical features \\
\hline Lawrence syndrome & Acquired & Presumed autoimmune & $\begin{array}{l}\text { Lipoatrophy in different stages with sparing of visceral } \\
\text { adipose, IR, steatohepatitis, dyslipidemia }\end{array}$ \\
\hline Barraquer-Simons syndrome & Acquired & Presumed autoimmune & $\begin{array}{l}\text { Symmetrical loss of adipose in a cephalocaudal pattern; } \\
\text { an increased gluteofemoral adipose is possible; no IR }\end{array}$ \\
\hline HAART-induced & Acquired & Unclear & $\begin{array}{l}\text { Distal and facial lipoatrophy creating an emaciated } \\
\text { appearance, with increased truncal and visceral adipose, } \\
\text { mild IR, hypertriglyceridemia }\end{array}$ \\
\hline $\begin{array}{l}\text { Bone marrow transplant- } \\
\text { associated lipodystrophy }\end{array}$ & Acquired & $\begin{array}{l}\text { Total body irradiation, } \\
\text { chemotherapy, allogenic } \\
\text { bone marrow transplant }\end{array}$ & Similar to those found in FPLD \\
\hline
\end{tabular}

\section{Acquired Generalized Lipodystrophy}

AGL, also known as Lawrence syndrome, is a rare disorder that arises later in life (Table 6). AGL is characterized by a loss of adipose tissue in childhood or adoles- cence, three times more common in women than men [95]. It is usually linked to autoimmune manifestations that can occur before or after the onset of the lipodystrophy. Although there is no familial inheritance, the presence of autoimmune diseases in the family members 
might help in the diagnosis. As shown in Figure 2, the loss of fat tissue is quite variable and often gradual, beginning with the involvement of a few body locations and then progressing to generalized [96]. Children may present an increased appetite due to low leptin plasma levels and linear growth, rarely acromegaloid features. More often patients present insulin resistance, diabetes, hypertriglyceridemia, hepatic steatosis, and fibrosis, which cause hepatomegaly and can eventually lead to steatohepatitis and cirrhosis. In about one-third of patients, acanthosis nigricans and loss of fat in the palms and soles are documented. Some fat accumulations can appear in the face, neck, or axillae. Activation of the classical complement pathway and low $\mathrm{C} 4$ complement levels have been connected to the dysfunction of adipocytes and presence of lipodystrophy, suggesting the involvement of this pathway in the pathogenesis of fat loss in AGL [97]. Furthermore, acquired lipodystrophies have also been found as a paraneoplastic manifestation of brain tumors in infants and young children [98].

\section{AGL Subtypes}

In consideration of the main phenotypic features, this syndrome has been further classified into AGL type 1 known as the panniculitis form, AGL type 2 that is the autoimmune disease, and AGL type 3 representing the idiopathic form. The presences of panniculitis and autoimmune pathologies are determined in about $25 \%$ of cases, while it has not yet been possible to identify the real causes [99] in the remaining cases with idiopathic variety.

In AGL type 1, localized atrophy may be the result of the healing of inflammatory subcutaneous nodules and then progress gradually to generalized lipodystrophy. Histologically, this type shows the infiltration of lymphocytes and histiocytes in the fat tissue, creating a granulomatous reaction and giant multinuclear cells. Patients usually develop lipodystrophy more slowly than the other subtypes and tend to register a lower prevalence of metabolic manifestations, specifically diabetes, and hypertriglyceridemia [100].

The most frequent autoimmune diseases related to AGL type 2 are Hashimoto's thyroiditis, Sjögren syndrome, chronically active hepatitis, juvenile rheumatoid arthritis, and in particular juvenile dermatomyositis. The pathogenetic mechanisms might be the establishment of a cell- or antibody-mediated autoimmune process that causes the destruction of adipocytes. Patients with this type tend to be older than those with the other AGL sub- types. Diabetes mellitus with severe insulin resistance is generally present and sometimes develops before the onset of lipodystrophy, requesting high doses of insulin [99].

\section{Acquired Partial Lipodystrophy}

APL comprises Barraquer-Simons syndrome, HIV-associated lipodystrophy, and bone marrow transplant-associated lipodystrophy (Table 6).

\section{Barraquer-Simons Syndrome}

Barraquer-Simons syndrome is a very rare disorder of unknown etiology that usually occurs in childhood and adolescence, typically before 15 years of age, more frequently in girls than boys (4:1 ratio). The lack of adipose tissue is typically symmetric, beginning from the upper side, specifically comprising the face giving children an aged appearance and then gradually spreading downward [96]. Fat loss usually affects the upper half of the body, with the arms showing well-defined musculature and apparent phlebomegaly. Fat depots can be found at the level of hips and legs. The metabolic involvement is not usually found, even though studies suggest that these complications have been underestimated [101]. Peculiar is the reduction of serum complement C3 levels and the presence of polyclonal immunoglobulin G or complement 3 nephritic factor present in about $90 \%$ of patients. This could lead to the development of membranoproliferative glomerulonephritis in about $20 \%$ of cases, which shows up about 10 years after the diagnosis and may cause kidney failure [50].

\section{Highly Active Antiretroviral Therapy-Induced}

Lipodystrophy in HIV-Infected Patients

Lipodystrophy is also found in HIV patients who underwent highly active antiretroviral therapy (HAART), including protease inhibitors or nucleoside reverse transcriptase inhibitors for at least 2 years. This syndrome appears in about $15 \%-20 \%$ of HIV patients within the first year of HAART and is now considered the most common form of lipodystrophy [102]. Among $210 \mathrm{HIV}$-infected children receiving HAART by clinical assessment, the prevalence of lipodystrophy was $30 \%$ overall [103]. The loss of adipose tissue gets worse during HAART therapy and once established, it does not regress, even if therapy is stopped. The phenotype is characterized by a great loss of fat from the face, paradoxical musculature of the extremities and depots in different body regions, such as chin (double chin), neck (buffalo hump), upper trunk (gynecomastia), and increased waist circumference due to intra- 
Table 7. Main metabolic derangements/ comorbidities in lipodystrophy syndromes
Lipodystrophy syndromes

CGL

- Insulin resistance

- Hyperinsulinemia

- Diabetes mellitus: especially during puberty, ketosis resistant

- Hypertriglyceridemia, leading to eruptive xanthomas and pancreatitis

- Low HDL levels

- Cardiovascular diseases, e.g., cardiomyopathy

- Focal segmental glomerulosclerosis

- Mental retardation

- Pathological fractures in the long bones after puberty

- Advanced bone age

- Polycystic ovaries and sterility (but successful pregnancies have been reported): all conditions caused by an excessive androgen production by ovaries and a loss of the pulsatile secretion of gonadotropins, probably due to insulin resistance and severe leptin deficiency

- No reproductive problems in men have been reported

FPLD

- Insulin resistance

- Abnormalities in both lipid and glucose metabolism

- Low leptin and adiponectin levels related to hyperphagia and reproductive changes

- Diabetes

- Cardiovascular diseases

- Hyperandrogenemia

AGL

- Insulin resistance

- Diabetes

- Hypertriglyceridemia

- Hepatic steatosis and fibrosis, causing hepatomegaly and consequently steatohepatitis and cirrhosis

- In women, irregular menstrual cycles and polycystic ovaries abdominal or visceral fat [104]. However, some patients have only lipohypertrophy or only lipoatrophy. Patients with an excess of visceral fat often develop insulin resistance, type 2 diabetes mellitus, hyperlipidemia, and accelerated atherosclerosis [105]. The metabolic pathogenesis probably derives from the inhibition of mitochondrial DNA and the dysfunction of respiratory chain with consequent reduction of the energy products caused by nucleoside reverse transcriptase inhibitors. Furthermore, protease inhibitors interfere with fat storage, increase adipocyte apoptosis and inhibit low-density lipoprotein receptor-related protein, which causes the accumulation of chylomicron and directly stops adipogenesis [106].

\section{Bone Marrow Transplant-Associated Lipodystrophy}

A large number of patients developed partial lipodystrophy following hematopoietic stem cell transplantation, pre- senting critical metabolic profiles later in adulthood, especially when they experienced a complicated disease course. Recent studies have shown that total body irradiation, chemotherapy, and allogeneic bone marrow transplant can cause lipodystrophy. The phenotypic characteristics are similar to those found in FPLD. This subtype is typically related to bone marrow transplant for children with leukemia [107].

\section{Diagnosis and Differential Diagnosis}

The diagnosis and clinical management of lipodystrophy are demanding. The main metabolic derangements and abnormalities are characteristic of each lipodystrophy syndrome (Table 7). Although the peculiar phenotype of lipodystrophy allows the diagnosis already at birth in patients with CGL, the diagnosis is often more complex, often re- 
questing a multidisciplinary approach. Usually, the diagnosis is based on clinical assessment, so the patients with suspicious familial and clinical history and physical features deserve more specific examinations, such as biochemical studies, body composition testing, and metabolic status evaluation. The presence of regional or generalized lack of adipose tissue can be established by anthropometry, dual-energy Xray absorptiometry that measures the regional and total body fat percentage, and whole-body magnetic resonance imaging that can provide information on the pattern of fat loss [108]. In men, it is quite difficult to recognize the loss of adipose tissue, as they have lower normal body fat than women and present less severe metabolic complications. Test for glucose intolerance, serum lipids levels, liver function, and uric acid should be evaluated in each patient, except those with localized fat depots. Serum complement 3 and 4, complement 3 nephritic factor and urine tests for proteinuria should be evaluated in patients with APL and AGL. In CGL and MAD is recommended to detect lytic lesions in bones and skeletal malformations by performing an X-ray. For patients with suspicious development of cardiovascular problems (cardiomyopathy or coronary heart disease), electrocardiography, Holter monitoring, echocardiography, and stress test should be performed. Although leptin has been considered as a marker of lipodystrophy, there are no defined serum leptin levels that determine or rule out the diagnosis. The reason is that serum leptin assays are not standardized and leptin concentrations, especially in patients with partial forms, overlap the general population. However, leptin can be useful in the choice of therapy [96]. Confirmatory genetic testing is helpful when there is a high suspicion of familial lipodystrophies.

Lipodystrophies should be considered in differential diagnosis of patients with early diabetes, severe hypertriglyceridemia, hepatic steatosis, hepatosplenomegaly, acanthosis nigricans, and polycystic ovarian syndrome. The research of the lack of subcutaneous fat in lean patients with these dismetabolic states should confirm the diagnosis of lipodystrophy. Furthermore, several conditions may cause severe weight loss, such as malnutrition, anorexia nervosa, cancer cachexia, chronic infections, uncontrolled diabetes mellitus, thyrotoxicosis, adrenocortical insufficiency, HIV-associated wasting, all plausible identities of differential diagnosis. Anyhow, thanks to a deeper investigation, a correct differentiation might be reached [100].

Patients with generalized lipodystrophy tend to develop acute pancreatitis, cirrhosis, end-stage renal disease, and blindness, often due to a severe diabetic condition. The main causes of death in FPL patients are, instead, coronary heart disease, cardiomyopathy, or arrhythmia [109]. HIV-affected patients with lipodystrophy are pre- disposed to die of coronary heart disease [110]. Renal failure can present in patients with APL who developed membranoproliferative glomerulonephritis.

\section{Treatment}

Lipodystrophy is a gradual and life-lasting disease that can sometimes cause death. There is not a curative therapy. In fact, today no available treatment can reverse the state of the pathology. However, current and novel therapeutic opportunities might prevent or ameliorate the several metabolic comorbidities associated with the disease. Similar to obesity, the first approach is diet. Particularly, reduced dietary energy uptake, especially in adults, very low-fat diets in those cases with acute pancreatitis induced by chylomicronemia. In addition, specialized dietary needs for children, taking into consideration the correct requirements for growth and avoiding overfeeding that can worsen hepatic steatosis. Exercise is also important: patients with lipodystrophy have registered positive effects on their metabolic complications doing regular intense physical activity, in particular in the improvement of insulin sensitivity. However, strenuous exercise should be avoided in individuals with cardiac problems, and contact sports should not be practiced by patients with hepatosplenomegaly and lytic bone lesions [96].

Thus, treatment of diabetes is first line and includes primarily metformin, even though some patients may need further agents, such as insulin. In case the daily requirements of insulin are very high, ultraconcentrated insulin analogs are useful. GLP1-receptor agonist could be considered in the context of hyperglycemia and hyperphagia due to leptin deficiency, but their use is allowed in patients without a clinical history of acute pancreatitis nor major hypertriglyceridemia. However, no studies on the use of this medication have been conducted so far [111].

Moreover, fibrates are prescribed in presence of hypertriglyceridemia, statins are essential with the aim to decrease LDL-cholesterol levels, ACE-inhibitors, and angiotensin-2 receptor antagonists (sartans) in case of arterial hypertension, since several lipodystrophic patients have cardiovascular diseases and need serial cardiological checks. Another important issue is the impact that the phenotype of this disease has on patients, causing significant psychological distress. Thus, injectable fillers, plastic surgery, and bariatric surgery may help, together with counseling and a pain management program, taking into account the elevated degrees of depression and anxiety reported in these patients $[112,113]$. 
Since the loss of fat is related to reduce concentrations of the metabolic regulatory adipokines leptin and adiponectin, the first approach to ameliorate metabolism is the substitution of leptin with the use of recombinant leptin (metreleptin) [114]. Metreleptin obtained a European Marketing Authorization in 2018 and has a key role in contrasting ectopic fat depots, by determining a decrease in appetite and reduction of food intake, common traits in patients with leptin deficiency and by stimulating insulin sensitivity. In particular, metreleptin not only improves insulin sensitivity but is also able to reduce hypertriglyceridemia, hyperglycemia, hepatic steatosis, liver volume, serum aminotransferase levels and to ameliorate insulin secretion. Essentially, it improves the metabolic profile in generalized lipodystrophy patients. In fact, treatment with metreleptin has efficacy even after the reduction or discontinuation of anti-diabetes therapy, even allowing its interruption [115].

The indication for metreleptin is the need to treat the metabolic complications in the context of leptin deficien$\mathrm{cy}$, together with diet, from 2 years of age in congenital and acquired generalized forms of lipodystrophy and from 12 years of age in familial and acquired partial forms of lipodystrophy, when standard therapies are not able to reach an adequate metabolic control and in case pre-therapeutic serum leptin is less than $4 \mathrm{ng} / \mathrm{mL}$ [21]. In partial forms, metreleptin is linked with normalization of both serum leptin and triglycerides levels, but with an absent improvement in glycemic control in case of severe hypoleptinemia and Dunnigan syndrome. It has been demonstrated that the efficacy of metreleptin is higher in cases of patients with worse metabolic values compared to those with better conditions after 1 year [116].

The most frequent side effects registered are local reactions at injection sites, headache, hypoglycemia, causing decrease of insulin dose, weight loss, being part of the therapeutic effect. None of these effects have required discontinuation of therapy. However, antimetreleptin antibodies have been identified in 36 out of 43 patients examined in a study. In addition, 2 patients had neutralizing antibodies, condition connected to infections, and metabolic imbalance [117]. The possibility that the neutralizing antibody may attenuate the effect of endogenous leptin along with metreleptin has to be considered. Hence, expected benefits and adverse effects should be carefully pondered before the onset of metreleptin therapy [118]. Further severe adverse effects may occur, linked not to metreleptin treatment, but to the underlying lipodystrophy syndrome. This is the case of T-cell lymphoma often registered in patients with AGL, pancreatitis, advanced stage liver, and kidney diseases $[119,120]$. However, in these patients, a direct relationship between metreleptin treatment and development of lymphomas has been registered. Indeed, the indication for the metreleptin therapy, considering its immunomodulatory role, should be wisely deliberated in patients with hematopoietic abnormalities [52].

\section{Conclusion}

Lipodystrophies, congenital, or acquired, include a group of diseases characterized by a reduction or lack of adipose tissue, related to metabolic consequences, such as insulin resistance, dyslipidemia, and hepatic steatosis, the same found in obesity. After all, the metabolism of adipose tissue and the mechanisms of metabolic syndrome can be further explained by considering the pathophysiology of lipodystrophy syndromes, despite their rarity. Diagnosis is often challenging since lipodystrophy can be incorrectly recognized as other conditions. A curative therapy is not available so far, so treatment is based on improving the several comorbidities associated with lipodystrophy. Replacement with metreleptin has demonstrated to be effective in reaching glucose and lipid control. This way seems to be promising for the management of the metabolic complications; however, further longterm studies are needed to explore novel therapeutic opportunities in these relevant diseases.

\section{Conflict of Interest Statement}

F. Chiarelli is an Editorial Board Member of Hormone Research in Paediatrics. The other author has no conflicts of interest to declare.

\section{Funding Sources}

This review did not receive any funding. F. Chiarelli is an Editorial Board Member of Hormone Research in Paediatrics.

\section{Author Contributions}

Each author has made substantial contributions to the conception or design of the work, participated in drafting the work or revising it critically for important intellectual content, approved the final version to be published, and agreed to be accountable for all aspects of the work in ensuring that questions related to the accuracy or integrity of any part of the work are appropriately investigated and resolved. 


\section{References}

1 Huang-Doran I, Sleigh A, Rochford JJ, O'Rahilly S, Savage DB. Lipodystrophy: metabolic insights from a rare disorder. J Endocrinol. 2010;207(3):245-55.

2 Hussain I, Garg A. Lipodystrophy syndromes. Endocrinol Metab Clin North Am. 2016; 45(4):783-97.

3 Melvin A, O'Rahilly S, Savage DB. Genetic syndromes of severe insulin resistance. Curr Opin Genet Dev. 2018;50:60-7.

4 Freitas P, Carvalho D. Lipodystrophy: beyond generalization? Panminerva Med. 2013;55(3): 253-68.

5 Melvin A, Adams C, Flanagan C, Gaff L, Gratton $\mathrm{B}$, Gribble F, et al. Roux-en-Y gastric bypass surgery in the management of familial partial lipodystrophy type 1 . J Clin Endocrinol Metab. 2017;102(10):3616-20.

6 Grundfest-Broniatowski S, Yan JL, Kroh M, Kilim H, Stephenson A. Successful treatment of an unusual case of FPLD2: the role of Roux-en$Y$ gastric bypass: case report and literature review. J Gastrointest Surg. 2017;21(4):739-43.

7 Ciudin A, Baena-Fustegueras JA, Fort JM, Encabo G, Mesa J, Lecube A. Successful treatment for the Dunnigan-type familial partial lipodystrophy with Roux-en-Y gastric bypass. Clin Endocrinol. 2011;75(3):403-4.

8 Cuthbertson DJ, Steele T, Wilding JP, Halford JC, Harrold JA, Hamer M, et al. What have human experimental overfeeding studies taught us about adipose tissue expansion and susceptibility to obesity and metabolic complications? Int J Obes. 2017;41(6):853-65.

9 Zammouri J, Vatier C, Capel E, Auclair M, Storey-London C, Bismuth E, et al. Molecular and cellular bases of lipodystrophy syndromes. Front Endocrinol. 2022;12:1-16.

10 Chiquette E, Oral EA, Garg A, Araújo-Vilar D, Dhankhar P. Estimating the prevalence of generalized and partial lipodystrophy: findings and challenges. Diabetes Metab Syndr Obes. 2017;10:375-83

11 Angelidi AM, Filippaios A, Mantzoros CS. Severe insulin resistance syndromes. J Clin Invest. 2021;131(4):e142245.

12 Chan JL, Oral EA. Clinical classification and treatment of congenital and acquired lipodystrophy. Endocr Pract. 2010;16(2):310-23.

13 Cortés VA, Fernández-Galilea M. Lipodystrophies: adipose tissue disorders with severe metabolic implications. J Physiol Biochem. 2015;71(3):471-8.

14 Garg A. Acquired and Inherited Lipodystrophies. N Engl J Med. 2004;350(12):1220-34.

15 Nolis T. Exploring the pathophysiology behind the more common genetic and acquired lipodystrophies. J Hum Genet. 2014;59(1): 16-23.

16 Garg A. Lipodystrophies. Am J Med. 2000; 108(2):143-52

17 Patni N, Garg A. Congenital generalized lipodystrophies: new insights into metabolic dysfunction. Nat Rev Endocrinol. 2015;11(9): 522-34.
18 Seip M, Trygstad O. Generalized lipodystrophy, congenital and acquired (lipoatrophy). Acta Paediatr Suppl. 1996;413:2-28.

19 Maguire M, Lungu A, Gorden P, Cochran E Stratton P. Pregnancy in a woman with congenital generalized lipodystrophy leptin's vital role in reproduction. Obstet Gynecol. 2012;119(2 Pt 2):452-5.

20 Miranda DM, Wajchenberg BL, Calsolari MR, Aguiar MJ, Silva JMCL, Ribeiro MG, et al. Novel mutations of the BSCL2 and AGPAT2 genes in 10 families with BerardinelliSeip congenital generalized lipodystrophy syndrome. Clin Endocrinol. 2009;71(4):512-

21 Diker-Cohen T, Cochran E, Gorden P, Brown RJ. Partial and generalized lipodystrophy: comparison of baseline characteristics and response to metreleptin. J Clin Endocrinol Metab. 2015;100(5):1802-10.

22 Rêgo AG, Mesquita ET, Faria CA, Rêgo MA, Baracho Mde F, Santos MG, et al. Cardiometabolic abnormalities in patients with Berardinelli-Seip syndrome. Arq Bras Cardiol. 2010; 94(1):109-18.

23 Javor ED, Moran SA, Young JR, Cochran EK, Depaoli AM, Oral EA, et al. Proteinuric nephropathy in acquired and congenital generalized lipodystrophy: baseline characteristics and course during recombinant leptin therapy. J Clin Endocrinol Metab. 2004;89(7): 3199-207.

24 Shinya T, Sato S, Akaki S, Ogata T, Kato K, Tone A, et al. Computed tomography findings of congenital generalized lipodystrophy: multiple nodular fatty liver and diffuse sclerosis of bones. Radiat Med. 2007;25(9):484-7.

25 Christensen JD, Lungu AO, Cochran E, Collins MT, Gafni RI, Reynolds JC, et al. Bone mineral content in patients with congenital generalized lipodystrophy is unaffected by metreleptin replacement therapy. J Clin Endocrinol Metab. 2014;99(8):E1493-500.

26 Berardinelli W. An undiagnosed endocrinometabolic syndrome: report of 2 cases. J Clin Endocrinol Metab. 1954;14(2):193-204.

27 Seip M. Lipodystrophy and gigantism with associated endocrine manifestations. A new diencephalic syndrome? Acta Paediatr. 1959;48: 555-74.

28 Agarwal AK, Arioglu E, de Almeida S, Akkoc $\mathrm{N}$, Taylor SI, Bowcock AM, et al. AGPAT2 is mutated in congenital generalized lipodystrophy linked to chromosome $9 \mathrm{q} 34$. Nat Genet. 2002;31(1):21-3.

29 Agarwal AK. Lysophospholipid acyltransferases: 1-acylglycerol-3-phosphate O-acyltransferases. from discovery to disease. Curr Opin Lipidol. 2012;23(4):290-302.

30 Simha V, Garg A. Phenotypic heterogeneity in body fat distribution in patients with congenital generalized lipodystrophy caused by mutations in the AGPAT2 or Seipin genes. J Clin Endocrinol Metab. 2003;88(11):5433-7.
31 Gale SE, Frolov A, Han X, Bickel PE, Cao L, Bowcock A, et al. A regulatory role for 1-acylglycerol-3-phosphate-O-acyltransferase 2 in adipocyte differentiation. J Biol Chem. 2006; 281(16):11082-9.

32 Subauste AR, Das AK, Li X, Elliot B, Evans C Azzouny MEL, et al. Alterations in lipid signaling underlie lipodystrophy secondary to AGPAT2 mutations. Diabetes. 2012;61(11): 2922-31.

33 Agarwal AK, Garg A. Congenital generalized lipodystrophy: significance of triglyceride biosynthetic pathways. Trends Endocrinol Metab. 2003;14(5):214-21.

34 Cartwright BR, Binns DD, Hilton CL, Han S, Gao Q, Goodman JM. Seipin performs dissectible functions in promoting lipid droplet biogenesis and regulating droplet morphology. Mol Biol Cell. 2015;26(4):726-39.

35 Yang W, Thein S, Guo X, Xu F, Venkatesh B, Sugii $S$, et al. Seipin differentially regulates lipogenesis and adipogenesis through a conserved core sequence and an evolutionarily acquired C-terminus. Biochem J. 2013; 452(1):37-44.

36 Cartwright BR, Goodman JM. Seipin: from human disease to molecular mechanism. J Lipid Res. 2012;53(6):1042-55.

37 Sim MFM, Dennis RJ, Aubry EM, Ramanathan N, Sembongi H, Saudek V, et al. The human lipodystrophy protein seipin is an ER membrane adaptor for the adipogenic PA phosphatase lipin 1. Mol Metab. 2013;2(1): 38-46.

38 Payne VA, Grimsey N, Tuthill A, Virtue S, Gray SL, Nora ED, et al. The human lipodystrophy gene BSCL2/Seipin may be essential for normal adipocyte differentiation. Diabetes. 2008;57(8):2055-60.

39 Van Maldergem L, Magré J, Khallouf TE, Gedde-Dahl T, Delépine M, Trygstad O, et al. Genotype-phenotype relationships in Berardinelli-Seip congenital lipodystrophy. J Med Genet. 2002;39(10):722-33.

40 Schuster J, Khan TN, Tariq M, Shaiq PA, Mäbert K, Baig SM, et al. Exome sequencing circumvents missing clinical data and identifies a BSCL2 mutation in congenital lipodystrophy. BMC Med Genet. 2014;15:71.

41 Engelman JA, Zhang XL, Galbiati F, Lisanti MP. Chromosomal localization, genomic organization, and developmental expression of the murine caveolin gene family (Cav-1, -2 , and -3) Cav-1 and Cav-2 genes map to a known tumor suppressor locus (6-A2/7q31). FEBS Lett. 1998;429(3):330-6.

42 Kim CA, Delépine M, Boutet E, El Mourabit $\mathrm{H}$, Le Lay S, Meier M, et al. Association of a homozygous nonsense caveolin-1 mutation with berardinelli-seip congenital lipodystrophy. J Clin Endocrinol Metab. 2008;93(4): 1129-34.

43 Parton RG, Simons K. The multiple faces of caveolae. Nat Rev Mol Cell Biol. 2007;8(3): 185-94. 
44 Briand N, Prado C, Mabilleau G, Lasnier F, Le Lièpvre X, Covington JD, et al. Caveolin-1 expression and cavin stability regulate caveolae dynamics in adipocyte lipid store fluctuation. Diabetes. 2014;63(12):4032-44.

45 Liu L, Pilch PF. A critical role of cavin (polymerase I and transcript release factor) in caveolae formation and organization. J Biol Chem. 2008;283(7):4314-22.

46 Perez-Diaz S, Johnson LA, DeKroon RM, Moreno-Navarrete JM, Alzate O, FernandezReal JM, et al. Polymerase I and transcript release factor (PTRF) regulates adipocyte differentiation and determines adipose tissue expandability. FASEB J. 2014;28(8):3769-79.

47 Rajab A, Straub V, McCann LJ, Seelow D, Varon R, Barresi R, et al. Fatal cardiac arrhythmia and long-QT syndrome in a new form of congenital generalized lipodystrophy with muscle rippling (CGL4) due to PTRF-CAVIN mutations. PLoS Genet. 2010;6(3):e1000874.

48 Simha V, Agarwal AK, Aronin PA, Iannaccone ST, Garg A. Novel subtype of congenital generalized lipodystrophy associated with muscular weakness and cervical spine instability. Am J Med Genet A. 2008;146A(18): 2318-26.

49 Shastry S, Delgado MR, Dirik E, Turkmen M, Agarwal AK, Garg A. Congenital generalized lipodystrophy, type 4 (CGL4) associated with myopathy due to novel PTRF mutations. Am J Med Genet A. 2010;152A(9):2245-53.

50 Araújo-Vilar D, Santini F. Diagnosis and treatment of lipodystrophy: a step-by-step approach. J Endocrinol Invest. 2019;42(1):6173.

51 Melvin A, Stears A, Savage DB. Recent developments in lipodystrophy. Curr Opin Lipidol. 2019;30(4):284-90.

52 Özen S, Akıncı B, Oral EA. Current diagnosis, treatment and clinical challenges in the management of lipodystrophy syndromes in children and young people. J Clin Res Pediatr Endocrinol. 2020;12(1):17-28.

53 Vigouroux C, Caron-Debarle M, Le Dour C, Magré J, Capeau J. Molecular mechanisms of human lipodystrophies: From adipocyte lipid droplet to oxidative stress and lipotoxicity. Int J Biochem Cell Biol. 2011;43(6):862-76.

54 Wong SPY, Huda M, English P, Bargiotta A, Wilding JPH, Johnson A, et al. Adipokines and the insulin resistance syndrome in familial partial lipodystrophy caused by a mutation in lamin A/C. Diabetologia. 2005;48(12): 2641-9.

55 Mathew H, Castracane VD, Mantzoros C. Adipose tissue and reproductive health. Metabolism. 2018;86:18.

56 Blüher M, Mantzoros CS. From leptin to other adipokines in health and disease: Facts and expectations at the beginning of the 21st century. Metabolism. 2015;64(1):131-45.

57 Rubio-Cabezas O, Puri V, Murano I, Saudek V, Semple RK, Dash S, et al. Partial lipodystrophy and insulin resistant diabetes in a patient with a homozygous nonsense mutation in CIDEC. EMBO Mol Med. 2009;1(5):280-7.
58 Dib K, Whitehead JP, Humphreys PJ, Soos MA, Baynes KCR, Kumar S, et al. Impaired activation of phosphoinositide 3-kinase by insulin in fibroblasts from patients with severe insulin resistance and pseudoacromegaly: A disorder characterized by selective postreceptor insulin resistance. J Clin Invest. 1998; 101(5):1111-20.

59 Bagias C, Xiarchou A, Bargiota A, Tigas S. Familial partial lipodystrophy (FPLD): recent insights. Diabetes Metab Syndr Obes. 2020; 13:1531-44.

60 Cao H, Hegele RA. Nuclear lamin A/C R482Q mutation in Canadian kindreds with Dunnigan-type familial partial lipodystrophy. Hum Mol Genet. 2000;9(1):109-12.

61 Maraldi NM, Lattanzi G, Squarzoni S, Capanni C, Cenni V, Manzoli FA. Implications for nuclear organization and gene transcription of lamin A/C specific mutations. Adv Enzyme Regul. 2005;45(1):1-16.

62 Andre P, Schneebeli S, Vigouroux C, Lascols $\mathrm{O}$, Schaaf M, Chevalier P. Metabolic and cardiac phenotype characterization in 37 atypical Dunnigan patients with nonfarnesylated $\mathrm{mu}-$ tated prelamin A. Am Heart J. 2015;169(4): 587-93.

63 Garg A, Peshock RM, Fleckenstein JL. Adipose tissue distribution pattern in patients with familial partial lipodystrophy (Dunnigan variety). J Clin Endocrinol Metab. 1999; 84(1):170-4.

64 Varlet AA, Helfer E, Badens C. Molecular and mechanobiological pathways related to the physiopathology of FPLD2. Cells. 2020;9(9):1-25.

65 Vantyghem MC, Pigny P, Maurage CA, Rouaix-Emery N, Stojkovic T, Cuisset JM, et al. Patients with familial partial lipodystrophy of the Dunnigan type due to a LMNA R482W mutation show muscular and cardiac abnormalities. J Clin Endocrinol Metab. 2004; 89(11):5337-46.

66 Pasotti M, Klersy C, Pilotto A, Marziliano N, Rapezzi C, Serio A, et al. Long-term outcome and risk stratification in dilated cardiolaminopathies. J Am Coll Cardiol. 2008;52(15): 1250-60.

67 Fountas A, Giotaki Z, Dounousi E, Liapis G, Bargiota A, Tsatsoulis A, et al. Familial partial lipodystrophy and proteinuric renal disease due to a missense c.1045C > T LMNA mutation. Endocrinol Diabetes Metab Case Reports. 2017;2017:17-0049.

68 Broekema MF, Savage DB, Monajemi H, Kalkhoven E. Gene-gene and gene-environment interactions in lipodystrophy: lessons learned from natural PPAR $\gamma$ mutants. Biochim Biophys Acta Mol Cell Biol Lipids. 2019; 1864(5):715-32.

69 Agarwal AK, Garg A. A novel heterozygous mutation in peroxisome proliferator-activated receptor- $\gamma$ gene in a patient with familial partial lipodystrophy. J Clin Endocrinol Metab. 2002;87(1):408-11.

70 Simha V, Garg A. Inherited lipodystrophies and hypertriglyceridemia. Curr Opin Lipidol. 2009;20(4):300-8.
71 Aprile M, Ambrosio MR, D'Esposito V, Beguinot $F$, Formisano $P$, Costa V, et al. PPARG in human adipogenesis: differential contribution of canonical transcripts and dominant negative isoforms. PPAR Res. 2014;2014: 537865.

72 Kobberling J, Dunnigan MG. Familial partial lipodystrophy: two types of an X linked dominant syndrome, lethal in the hemizygous state. J Med Genet. 1986;23(2):120-7.

73 Lotta LA, Gulati P, Day FR, Payne F, Ongen $\mathrm{H}$, Van De Bunt $\mathrm{M}$, et al. Integrative genomic analysis implicates limited peripheral adipose storage capacity in the pathogenesis of human insulin resistance. Nat Genet. 2017;49(1):1726.

74 Herbst KL, Tannock LR, Deeb SS, Purnell JQ, Brunzell JD, Chait A. Köbberling type of familial partial lipodystrophy: an underrecognized syndrome. Diabetes Care. 2003;26(6): 1819-24.

75 Ajjajia D, M'barekBen K, Mimmack ML, England C, Herscovitz H, Dong L, et al. Dual binding motifs underpin the hierarchical association of perilipins1-3 with lipid droplets. Mol Biol Cell. 2019;30(5):703-16.

76 Tansey JT, Sztalryd C, Hlavin EM, Kimmel $\mathrm{AR}$, Londos C. The central role of perilipin A in lipid metabolism and adipocyte lipolysis. IUBMB Life. 2004;56(7):379-85.

77 Gandotra S, Le Dour C, Bottomley W, Cervera P, Giral P, Reznik Y, et al. Perilipin deficiency and autosomal dominant partial lipodystrophy. N Engl J Med. 2011;364(8):740-8.

78 Jéru I, Vantyghem MC, Bismuth E, Cervera P, Barraud S, Auclair M, et al. Diagnostic challenge in PLIN1-associated familial partial lipodystrophy. J Clin Endocrinol Metab. 2019; 104(12):6025-32.

79 Laver TW, Patel KA, Colclough K, Curran J, Dale J, Davis N, et al. PLIN1 haploinsufficiency is not associated with lipodystrophy. J Clin Endocrinol Metab. 2018;103(9):3225-30.

80 Chen FJ, Yin Y, Chua BT, Li P. CIDE family proteins control lipid homeostasis and the development of metabolic diseases. Traffic. 2020;21(1):94-105.

81 Walther TC, Chung J, Farese RV. Lipid droplet biogenesis. Annu Rev Cell Dev Biol. 2017; 33:491-510.

82 Zolotov S, Xing C, Mahamid R, Shalata A, Sheikh-Ahmad M, Garg A. Homozygous LIPE mutation in siblings with multiple symmetric lipomatosis, partial lipodystrophy, and myopathy. Am J Med Genet A. 2017;173(1): 190-4.

83 Albert JS, Yerges-Armstrong LM, Horenstein RB, Pollin TI, Sreenivasan UT, Chai S, et al. Null mutation in hormone-sensitive lipase gene and risk of type 2 diabetes. N Engl J Med. 2014;370(24):2307-15.

84 Knebel B, Müller-Wieland D, Kotzka J. Lipodystrophies: disorders of the fatty tissue. Int J Mol Sci. 2020;21(22):8778. 
85 Novelli G, Muchir A, Sangiuolo F, HelblingLeclerc A, D'apice MR, Massart C, et al. Mandibuloacral dysplasia is caused by a mutation in LMNA-encoding lamin A/C. Am J Hum Genet. 2002;71(2):426-31.

86 Garavelli L, D’Apice MR, Rivieri F, Bertoli M, Wischmeijer A, Gelmini C, et al. Mandibuloacral dysplasia type A in childhood. Am J Med Genet A. 2009;149A(10):2258-64.

87 Agarwal AK, Fryns JP, Auchus RJ, Garg A. Zinc metalloproteinase ZMPSTE24, is mutated in mandibuloacral dysplasia. Hum Mol Genet. 2003;12(16):1995-2001.

88 Plasilova M, Chattopadhyay C, Pal P, Schaub NA, Buechner SA, Mueller H, et al. Homozygous missense mutation in the lamin $\mathrm{A} / \mathrm{C}$ gene causes autosomal recessive HutchinsonGilford progeria syndrome. J Med Genet. 2004;41(8):609-14

89 Eriksson M, Brown WT, Gordon LB, Glynn MW, Singer J, Scott L, et al. Recurrent de novo point mutations in lamin A cause Hutchinson-Gilford progeria syndrome. Nature. 2003;423(6937):293-8.

90 Dyment DA, Smith AC, Alcantara D, Schwartzentruber JA, Basel-Vanagaite L, Curry CJ, et al. Mutations in PIK3R1 cause SHORT syndrome. Am J Hum Genet. 2013; 93(1):158-66.

91 Chudasama KK, Winnay J, Johansson S, Claudi T, König R, Haldorsen I, et al. SHORT syndrome with partial lipodystrophy due to impaired phosphatidylinositol 3 kinase signaling. Am J Hum Genet. 2013;93(1):150-7.

92 Thauvin-Robinet C, Auclair M, Duplomb L, Caron-Debarle M, Avila M, St-Onge J, et al. PIK3R1 mutations cause syndromic insulin resistance with lipoatrophy. Am J Hum Genet. 2013;93(1):141-9.

93 Lessel D, Ozel AB, Campbell SE, Saadi A, Arlt MF, McSweeney KM, et al. Analyses of LMNA-negative juvenile progeroid cases confirms biallelic POLR3A mutations in Wiedemann-Rautenstrauch-like syndrome and expands the phenotypic spectrum of PYCR1 mutations. Hum Genet. 2018;137(11-12): 921-39.

94 Takenouchi T, Hida M, Sakamoto Y, Torii C, Kosaki R, Takahashi T, et al. Severe congenital lipodystrophy and a progeroid appearance: mutation in the penultimate exon of FBN1 causing a recognizable phenotype. Am J Med Genet A. 2013;161A(12):3057-62.

95 Misra A, Garg A. Clinical features and metabolic derangements in acquired generalized lipodystrophy case reports and review of the literature. Medicine. 2003;82(2):129-46.
96 Brown RJ, Araujo-Vilar D, Cheung PT, Dunger D, Garg A, Jack M, et al. The diagnosis and management of lipodystrophy syndromes: a multi-society practice guideline. J Clin Endocrinol Metab. 2016;101(12): 4500-11.

97 Savage DB, Semple RK, Clatworthy MR, Lyons PA, Morgan BP, Cochran EK, et al. Complement abnormalities in acquired lipodystrophy revisited. J Clin Endocrinol Metab. 2009;94(1):10-6.

98 Ceccarini G, Magno S, Gilio D, Pelosini C, Santini F. Autoimmunity in lipodystrophy syndromes. Presse Méd. 2021;50(3):104073.

99 Misra A, Peethambaram A, Garg A. Clinical features and metabolic and autoimmune derangements in acquired partial lipodystrophy: report of 35 cases and review of the literature. Medicine. 2004;83(1):18-34.

100 Garg A. Lipodystrophies: genetic and acquired body fat disorders. J Clin Endocrinol Metab. 2011;96(11):3313-25.

101 Akinci B, Koseoglu FD, Onay H, Yavuz S, Altay C, Simsir IY, et al. Acquired partial lipodystrophy is associated with increased risk for developing metabolic abnormalities. Metabolism. 2015;64(9):1086-95.

102 Finkelstein JL, Gala P, Rochford R, Glesby MJ, Mehta S. HIV/AIDS and lipodystrophy: implications for clinical management in resource-limited settings. J Int AIDS Soc. 2015;18(1):19033.

103 S0755498221000105.

104 Chen D, Misra A, Garg A. Lipodystrophy in human immunodeficiency virus-infected patients. J Clin Endocrinol Metab. 2002; 87(11):4845-56.

105 Estrada V, Serrano-Ríos M, Martínez Larrad MT, Villar NGP, González López A, Jesus Téllez M, et al. Leptin and adipose tissue maldistribution in HIV-infected male patients with predominant fat loss treated with antiretroviral therapy. J Acquir Immune Defic Syndr. 2002;29(1):32-40.

106 Andersen O. A characterisation of lowgrade inflammation and metabolic complications in HIV-infected patients. Dan Med J. 2016;63(10):B5291.

107 Adachi M, Oto Y, Muroya K, Hanakawa J, Asakura Y, Goto H. Partial lipodystrophy in patients who have undergone hematopoietic stem cell transplantation during childhood: an institutional cross-sectional survey. Clin Pediatr Endocrinol. 2017;26(2):99-108.

108 Handelsman Y, Oral EA, Bloomgarden ZT, Brown RJ, Chan JL, Einhorn D, et al. The clinical approach to the detection of lipodys- trophy: an AACE consensus statement. Endocr Pract. 2013;19(1):107-16.

109 Subramanyam L, Simha V, Garg A. Overlapping syndrome with familial partial lipodystrophy, Dunnigan variety and cardiomyopathy due to amino-terminal heterozygous missense lamin A/C mutations. Clin Genet. 2010;78(1):66-73.

110 Grinspoon S, Carr A. Cardiovascular risk and body-fat abnormalities in HIV-infected adults. N Engl J Med. 2005;352(1):48-62.

111 Banning F, Rottenkolber M, Freibothe I, Seissler J, Lechner A. Insulin secretory defect in familial partial lipodystrophy Type 2 and successful long-term treatment with a glucagon-like peptide 1 receptor agonist. Diabet Med. 2017;34(12):1792-4.

112 Sollier C, Vatier C, Capel E, Lascols O, Auclair M, Janmaat S, et al. Lipodystrophic syndromes: from diagnosis to treatment. Ann Endocrinol. 2020;81(1):51-60.

113 Foss-Freitas MC, Akinci B, Luo Y, Stratton A, Oral EA. Diagnostic strategies and clinical management of lipodystrophy. Expert Rev Endocrinol Metab. 2020;15(2):95-114.

114 Tsoukas MA, Farr OM, Mantzoros CS Leptin in congenital and HIV-associated lipodystrophy. Metabolism. 2015;64(1):4759.

115 Vatier C, Fetita S, Boudou P, Tchankou C, Deville L, Riveline JP, et al. One-year metreleptin improves insulin secretion in patients with diabetes linked to genetic lipodystrophic syndromes. Diabetes Obes Metab. 2016;18(7):693-7.

116 Moahad Dar NA, Xu J. Efficacy and safety of metreleptin in patients with partial lipodystrophy: lessons from an expanded access program. J Diabetes Metab. 2016;7(3):659.

117 Deeks E. Metreleptin in lipodystrophy: a profile of its use. Drugs Ther Perspect. 2019; 35(5):201-8.

118 Tanaka T, Kusakabe T, Ebihara K, AizawaAbe M, Aotani D, Yorifuji T, et al. Practice guideline for lipodystrophy syndromes: clinically important diseases of the Japan Endocrine Society (JES). Endocr J. 2021; 68(9):1027-42.

119 Brown RJ, Chan JL, Jaffe ES, Cochran E, Depaoli AM, Gautier JF, et al. Lymphoma in acquired generalized lipodystrophy. Leuk Lymphoma. 2016;57(1):45-50.

120 Chan J, Lutz K, Cochran E, Huang W, Peters Y, Weyer C, et al. Clinical effects of longterm metreleptin treatment in patients with lipodystrophy. Endocr Pract. 2011;17(6): 922-32. 